\title{
SOBRE LAS RELACIONES ENTRE ECONOMIA, DEMOCRACIA Y REVOLUCIÓN
}

\author{
ABOUT THE RELATIONSHIP AMONG ECONOMICS, DEMOCRACY \\ AND REVOLUTION
}

\author{
José Luis Coraggio 1 \\ Universidad Nacional de General Sarmiento, Los Polvorines (Bs.As.), Argentina
}

\begin{abstract}
Resumen: En este trabajo se proponen algunas definiciones básicas para orientar una investigación sobre los procesos recientes en América Latina bajo gobiernos con proyectos nacional-populares, usualmente denominados de "nuevas izquierdas". Se propone un paralelo entre economía y democracia sustantiva, por un lado, y democracia a formal y sustantiva, por el otro. Se esquematizan varios senderos lógicamente posibles de transformación política y económica y se plantean algunas hipótesis sobre su interdependencia. La hipótesis principal es que, para evitar ser revertidos, estos procesos requieren una radicalización de la democracia.
\end{abstract}

Palabras-clave: America Latina; Democracia; Revolución.

Abstract: This paper intends to provide some elementary definitions to guide an investigation about the recent Latin American processes headed new left governments. A parallel is proposed between formal economy/formal democracy, on the one hand, and substantive economy/substantive democracy on the other. Possible logical paths of political and economic transformation are sketched and some hypotheses regarding their mutual causality are advanced. The main hypothesis posed is that, for avoid reversibility; these processes should include an effective radicalization of democracy.

Keywords: Latin America; Democracy; Revolution.

\footnotetext{
${ }^{1}$ Doctor, Investigador del Instituto del Conurbano de la Universidad Nacional de General Sarmiento;

E-mail: <jlcoraggio@me.com>. Recibido en: 16.09.2016; acepto en: 07.11.2016.
} 


\section{INTRODUCCIÓN}

En América Latina están ocurriendo procesos sociales y políticos que han sido caracterizados como de "nuevas izquierdas gobernantes" (CORAGGIO y LAVILLE, 2014, "a") y, en algunos casos, como "revoluciones del Siglo XXI". Es imperioso explicar y comprender esos procesos que caracterizan lo nuevo en la región, y seguramente esa indagación no se hará sin conceptos. Este trabajo propone explicitar un marco conceptual básico, casi elemental, para analizar qué clase de transformaciones se han venido experimentando en esos casos y en qué sentido pueden ser consideradas revolucionarias.

Dado que las ciencias sociales participan de un campo de fuerzas donde se disputa la hegemonía, cualquier concepto derivado de un pensamiento crítico debe ubicarse por referencia a los hegemónicos. Propondremos como horizonte imaginario y deseable la conjunción de una democracia y una economía sustantivas. En esto, será cuestionada la separación entre esfera política y esfera económica, así como los paradigmas de democracia formal y economía formal y su supuesta correspondencia virtuosa.

Los casos de Argentina, Bolivia, Brasil, Ecuador, Uruguay y Venezuela ${ }^{2}$, son tomados como referentes, individualmente y como conjunto dentro del contexto regional y global. Mucho hay para indagar: en qué consiste la diferencia de esos procesos respecto a las situaciones precedentes y en relación al espectro de los que suelen denominarse gobiernos "progresistas", en particular los socialdemócratas? En qué y por qué causas se diferencian entre ellos y cuáles son sus posibilidades de desarrollo a futuro? quienes han sido y pueden ser sus sujetos? Por último: qué significa ser de izquierda en esta región y en este momento histórico y qué perspectivas tienen los procesos y prácticas en que se encarnan?

La intención de este trabajo es plantear hipótesis de trabajo para una investigación que provea una mejor comprensión de la actualidad y la potencialidad de los procesos estudiados y de sus raíces históricas. Hay urgencia en esto, resultante de su vulnerabilidad actual o potencial, ya sea por sus contradicciones internas o por las fuerzas económicas y políticas, nacionales e internacionales desplegadas para abortarlos. Por lo tanto se requiere evitar que los tiempos académicos se desfasen de los que demandan los sujetos sociales involucrados. En consecuencia, no se pretende otra cosa que proponer unos pocos conceptos que pueden ser útiles para organizar un debate y una respuesta a esas preguntas que vaya mas allá de la mera opinión. ${ }^{3}$ Por otro lado, dado el estado líquido del campo teórico, se justifica que la elucidación de los conceptos pueda ser provisoria e incompleta, pretendiendo orientar investigaciones empíricas en su fase inicial y abiertos a su rectificación sobre la marcha.

\footnotetext{
${ }^{2}$ Esa selección de países es la adoptada por el proyecto "Democracias en Revolución y Revoluciones en Democracia", dirigido por Ramón Torres y coordinado por el Instituto de Altos Estudios Nacionales del Ecuador (IAEN). Desde nuestro punto de vista tienen fuertes diferencias, pero un rasgo común es que en todos ellos se han establecido regímenes con representantes elegidos mediante procedimientos de la democracia formal, para cumplir un programa antineoliberal, impulsado por movimientos sociales y/o políticos que expresaban a buena parte de los sectores populares de esas sociedades que percibían a los agentes políticos del neoliberalismo como un enemigo común. Esto abarcó desde la masa de población carenciada y excluida hasta los sectores medios y los pequeños y mediano empresarios afectados por las políticas llevadas a cabo por gobiernos que pueden ser calificados como socialdemócratas, todo lo cual induce a pensar en una orientación de "nueva izquierda". Tres de esos líderes proponen un Socialismo del Siglo XXI (en los países andinos); los otros tres son políticos o activistas sociales con orientación popular y fuertes antecedentes de resistencia al neoconservadurismo político y su programa económico neoliberal.

${ }^{3} \mathrm{Al}$ elaborar estas notas no se han seguido a cabalidad las reglas del trabajo académico, que supone, entre otras cosas, dar cuenta de una parte relevante de lo previamente escrito sobre la cuestión que encaramos.
} 


\section{CONCEPTOS GENERALES: ECONOMÍA}

La economía formal, ${ }^{4}$ que se intenta justificar en postulados antropológicos (homo economicus) construye un tipo ideal de sistema económico: la economía de mercado. Ésta sería la única forma de institucionalización de los procesos económicos de producción, distribución, circulación y consumo de manera de asegurar que los comportamientos económicos cotidianos sean racionales y, por tanto, que lo sea la economía como un todo.

Tal racionalidad es instrumental, maximizadora de la utilidad individual y, como consecuencia, de la acumulación, supuestamente sin límites éticos. Dentro de las reglas del mercado (entre otras: cumplimiento de los contratos, respeto a la propiedad privada, papel subsidiario del Estado) cada individuo se apropia, para consumir o acumular, de lo que logra con su participación en la producción de bienes o servicios. Se postula que en tal situación la economía tenderá a un equilibrio óptimo en que se maximice el bienestar de la sociedad.

Para que esto se realice deben cumplirse varias condiciones: individuación, competencia, transparencia, información plena, libertad de empresa (sin restricciones desde la política o la sociedad organizada), separación de la esfera económica de la política y de la cultural (vistas como obstáculos, aceptables en tanto sean mercantilizadas). Los dos roles que asumen los miembros de la sociedad son el de productor y el de consumidor. En suma, debe darse (o construirse) una autonomía del mercado como mecanismo autorregulado, reduccionista y homogeneizante. Valores como la justicia o la solidaridad también son considerados obstáculos para la racionalidad económica.

Cabe aclarar que, aún siendo siendo críticos del neoliberalismo y sus fundamentos teóricos, esto no implica que algunas formas propuestas por el pensamiento liberal no puedan/deban ser adoptadas como una contribución al bien común. ${ }^{5}$

La "economía real" hace referencia a las condiciones efectivas de institucionalización de los procesos económicos y de sus consecuencias en una sociedad concreta. Por ejemplo, en lo que hace a las formas de producción (tecnología, relaciones con la naturaleza, relaciones de cooperación y complementariedad), a las reglas que rigen el acceso a la propiedad y sus usos, los límites al extractivismo o a la desigualdad, a los mecanismos de distribución y redistribución de la riqueza, a los diversos modos de intercambio, de los cuales el mercado es solo uno, y al consumo. En fin, las formas particulares de organización y coordinación del metabolismo socio-natural (CORAGGIO, 2011).

Más allá de todo tipo ideal, en las economías empíricas coexisten conflictivamente diversos principios éticos que se manifiestan en las prácticas cotidianas, en las políticas públicas, en los discursos técnicos o intelectuales, así como en los proyectos sociales, lo que implica la presencia de una lucha por la hegemonía y, por tanto, de la política.

\footnotetext{
${ }^{4}$ Fue Karl Polanyi quién diferenció y contrapuso economía formal y economía sustantiva (POLANYI, 2012).

${ }^{5}$ En un trabajo reciente afirmamos que en general las izquierdas revolucionarias del Siglo XX pretendían, en primer lugar, restituir la democracia formal que venía siendo negada por el conservadurismo mediante el fraude, el golpe de estado y las dictaduras, buscando permitir la libre expresión de las mayorías en cuya defensa se planteaba la revolución. Lo que no significa que tales izquierdas no tuvieran un proyecto de radicalización de las instituciones de la democracia, de transformación de la matriz productiva y de las relaciones sociales de producción bajo la dirección/inducción del Estado.
} 
Necesitamos el concepto de economía real para referirnos al punto de partida empírico, que en nuestros países podríamos calificar como economía deforme o incompleta desde la perspectiva de cualquiera de las concepciones enunciadas: hay mercado pero está lejos del desarrollado en países centrales del sistema mundo y, por supuesto, del modelo ideal de mercado libre; hay reproducción de la vida digna para unos, pero una parte de la sociedad es puesta en condiciones de mera supervivencia biológica y expuesta a una muerte innecesaria.

Un asunto central es cómo se traducen o articulan las determinaciones económicas con las políticas. Reconociendo la diversidad de formas de producción y reproducción que coexisten más o menos articuladas en cada sociedad, considerarlas como capitalistas periféricas supone la centralidad del régimen de acumulación privada y el modo de regulación del conjunto a escala global, y allí la política y el Estado juegan un papel relevante.

Por su lado, la economía sustantiva se apoya en la crítica teórica y ética a la absolutización de la racionalidad instrumental del liberalismo económico (hoy neoliberalismo) que, sumado a lo anterior, propugna la adopción de procedimientos de cálculo motivados por la maximización de la utilidad individual, compitiendo todos contra todos, con resultados dispares entre quienes tienen éxito y quienes fracasan (lo que el mercado vendría a institucionalizar como principio absoluto de integración social de la economía). Por el contrario, la economía sustantiva afirma que la racionalidad instrumental debe estar subsumida por la racionalidad reproductiva de la vida (HINKELAMMERT y MORA, 2009), que supone que todos los seres humanos deben tener asegurado su sustento. Es desde esa perspectiva que se propone examinar la economía real, estableciendo reglas y normas específicas a ese campo de acción, reconociendo la existencia de una diversidad de motivaciones de los individuos o comunidades no reducibles al utilitarismo. (CAILLÉ, 2010)

Hemos propuesto la siguiente definición de Economía Social, inscripta en la corriente de la economía sustantiva ${ }^{6}$ : el sistema plural de instituciones, ${ }^{7}$ normas, valores y prácticas que organizan el proceso económico de producción, distribución, circulación y consumo, para generar las bases materiales de la realización de las necesidades y deseos legítimos de tod@s, para vivir con dignidad, con libertad responsable de opciones, en democracia y en equilibrio con la naturaleza. ${ }^{8}$

La definición formal afirma que no solo es posible sino que es necesario que los actores económicos, en tanto tales, prescindan de valores y principios éticos. No niega que tales valores existan, pero los clasifica como irracionales y no sujetos a análisis científicos (WEBER, 1964), cuando en realidad hay una ética del mercado (HINKELAMMERT y MORA, 2009; DUSSEL, 2014). Por su parte, la definición sustantiva incorpora

\footnotetext{
${ }^{6}$ Dos estudios emp iírecientes que incorporan elementos de esta aproximación son: Irene Ragazzini, Economías Comunales en la Mixteca. El alcance de las Instituciones Económicas Comunales en la Resistencia a la Economía de Mercado y la Construcción de Autonomía. Tesis de maestría en economía social - iv edición (2009-2011) Universidad Nacional de General Sarmiento, Buenos Aires, Argentina, y Erika Loritz, Comunidad y mercado. Tensiones y complementariedades en la economía de Curahuara de Carangas, Oruro, Bolivia. Tesis de Maestría en Economía Social, V Edición (2011-2013), UNGS, Buenos Aires, Argentina.

${ }^{7}$ Cuando decimos "instituciones" no nos limitamos a formas de organización o a sistemas normativos legales. Incluimos en un mismo plano de importancia las prácticas recurrentes, aunque no estén formalizadas (ejemplo: las formas de expresar demandas sociales particulares o de establecer un diálogo entre distintas interpretaciones del mandato constitucional).

${ }^{8}$ A partir del trabajo "Reinventar la izquierda en el Siglo XXI", a las definiciones que veníamos proponiendo agregamos la explicitación de la libertad y la democracia como componentes de sentido de la economía.
} 
explícitamente un principio ético: el imperativo de la reproducción de la vida humana y de la naturaleza en su conjunto.

Por otro lado, a diferencia de la teoría económica hegemónica, la teoría de la Economía Social no resultará de la mera construcción deductiva a partir de un principio económico (como podría postularse el de reciprocidad, encarnado en un imaginario homo reciprocans). Por el contrario, como parte de la corriente sustantivista, debe fundar y corroborar sus proposiciones con estudios históricos y antropológicos de economías empíricas, los que muestran que toda sociedad que perdure resuelve el problema económico (el sustento de todas y todos) combinando una pluralidad de principios entre los cuales Polanyi destaca los de autarquía, reciprocidad, redistribución e intercambio. Este último incluye, pero no exclusivamente, al de mercado. Esos estudios permiten también afirmar que la institucionalidad económica ha sido predominantemente una construcción política, en buena medida impuesta por la violencia. ${ }^{9}$

Mientras la economía de mercado sólo reconoce las necesidades que se pueden manifestar como demandas solventes, la Economía Social pone como principio ético orientador de la construcción de instituciones económicas la resolución de las necesidades de todas y todos. Esto no se reduce a las mal llamadas "básicas" (alimentación, salud, refugio y otras condiciones para la supervivencia como seres orgánicos). La vida humana de cuya reproducción se ocupa la economía sustantiva es una vida en comunidad, digna, integral, y por tanto incluye necesidades como las de participación, de conocimiento y reconocimiento, de participación, de soberanía. Todas ellas tienen condiciones y efectos materiales y requieren satisfactores sinérgicos antes que la salida consumista. (MAX-NEEF, 1986; ARANCIBIA, 2013) En esta línea, el concepto de riqueza de la economía social es el de la masa de medios útiles (bienes y servicios) para resolver necesidades, y no la masa de mercancías.

En cuanto a la relación entre política y economía, el régimen político y la forma de Estado existentes son considerados condiciones determinantes del tipo de integración social de los procesos económicos ${ }^{10}$ y por tanto entran en nuestro campo de análisis. Mientras que las dictaduras ignoran muchas de esas necesidades y para las mayorías reservan satisfactores singulares si es que no destructivos, la democracia representativa y la directa facilitan decisiones políticas válidas sobre su legitimación y plena realización. La democracia directa permite ampliar el conocimiento de lo inmediato, lo local, lo cotidiano, y la representativa puede habilitar el conocimiento de la totalidad social, del efecto de las estructuras sobre situaciones de vida cotidiana. ${ }^{11}$ Según el asunto de que se trate podrá ser más eficaz una u otra combinación de ambas, sin caer en un planteo puramente funcional que ignore el fundamento cultural de cada realidad. Esta es una de las razones por la cual economía, política y cultura no pueden desgajarse ni en la realidad ni en el pensamiento de lo concreto.

\section{CONCEPTOS GENERALES: DEMOCRACIA}

\footnotetext{
${ }^{9}$ Esto es ilustrado por la formación del sistema de mercados durante el Siglo XVIII a partir de los cercamientos, o la reciente institucionalización neoliberal de un mercado total de alcance global.

${ }^{10}$ La hipótesis de la Economía Social es que, cuando esa integración no se da atendiendo a las reivindicaciones de las mayorías, y el mercado es liberado de restricciones sociales y políticas orientadas por el bien común, las sociedades entran en un proceso destructivo, caotizándose, perdiendo cohesión, en lo que Polanyi denominó "desencastramiento".

${ }^{11}$ A nuestro juicio, las formas de democracia directa deben ser vigiladas y no pueden ser idealizadas, pues también pueden enmarcar prácticas clientelares, asambleas manipuladas, o funcionar alienadamente respecto al sistema global en que se insertan.
} 
Dentro de un marco democrático, no puede haber una revolución de la sociedad sin sujetos políticos complejos que se configuren dentro de esa misma sociedad y disputen la hegemonía. Una revolución es un proceso sostenido y prolongado, y tales sujetos son contingentes en su conformación, en parte por influencia de las coyunturas económicas. Esto no puede dejar de incidir en los alcances y la dinámica de los gobiernos de las "nuevas izquierdas".

Sin la pretensión de innovar con definiciones generales de democracia, vamos a partir de una diferenciación que consideramos relevante para el análisis de los procesos que nos convocan. Esa diferenciación, al alcance de la intuición, es la que se plantea entre democracia real, formal y sustantiva.

En la tradición liberal, la democracia es básicamente un sistema de formación y ejercicio del poder basado en la libre elección por la sociedad de sus representantes en el gobierno del Estado, la que se realiza periódicamente a través del voto del conjunto de los individuos clasificados como ciudadanos. Dentro de esto hay variaciones: esas elecciones pueden ser directas o indirectas, en ciertos casos pueden darse también decisiones plebiscitarias o por referéndum, algunos poderes como el de los jueces pueden ser vitalicios, el régimen de gobierno puede ser presidencialista o colegiado y puede haber situaciones tipificadas en que los ciudadanos revoquen el mandato otorgado.

La organización colectiva que corresponde es el partido político, asociación libre de ciudadanos con valores o propuestas compartidas, que compiten proponiendo sus candidatos a representantes. Esto aseguraría que los gobernantes de turno no tengan un monopolio de la representación sino que estén sujetos a compulsas recurrentes y al escrutinio de sus acciones.

Se postula que adoptar estos procedimientos asegurará que se defina un interés general, que reflejaría los pesos relativos de los sectores particulares diferenciados por sus intereses materiales o preferencias, de clase, género, etnia, religiosos, ideológicos, regionales, etc. derivados de determinaciones funcionales, identitarias o histórico-culturales constitutivas. Por supuesto que hablar de "pesos" no implica ponderar las calidades de las reivindicaciones expresadas, salvo la obvia de que la decisión colectiva resultante no anule el sistema democrático mismo.

En paralelo con la economía formal, al calificar esa institucionalización de lo político como "democracia formal" se indica que en última instancia se define por los procedimientos para elegir a las autoridades de una sociedad, lo que por ello las haría legítimas.

Tal como ocurre con la noción de "equilibrio" económico, al que permitiría llegar el juego de los intereses individuales expresados en el mercado, la usual referencia al "interés general" resulta abstracta si no se introduce un principio ético como el de la reproducción y desarrollo de la vida de todos, que sería la última instancia del "bien común" o que respondería al "interés de todos" (HINKELAMMERT y MORA, 2009).

En principio, la propuesta formal no requiere justificar un gobierno por el contenido o los resultados de sus políticas públicas. Es legítimo por haber sido elegido por la mayoría, no por los efectos sociales que logra respecto a la realización de necesidades y derechos de la población representada. En otros términos, no se explica cómo la democracia formal logra mediar entre la diversidad de intereses particulares y el bien común. 
El tipo ideal de la democracia formal especifica algunos requerimientos para ser eficaz, como la igualdad de poder del voto, la garantía de una libertad negativa de las personas (ausencia de restricciones impuestas desde las instituciones políticas u otras), un comportamiento racional de los electores (que por ejemplo deje afuera los afectos, pulsiones, identificaciones). Supone asimismo una ciudadanía bien informada en una sociedad con transparencia. De hecho, prácticamente asimila el campo político a su tipo ideal de mercado.

Justamente, la Teoría de la Acción Racional propone extender la racionalidad instrumental utilitarista a toda actividad humana mediante su mercantilización, con lo que democracia formal y mercado serían coherentes. El voto es un medio para lograr fines. En todo caso, nadie elige sus autoridades por sí mismo, dada la atomización del pueblo en ciudadanos, aún si cabe la participación en ámbitos de asociación por afinidad (los partidos). Se trata entonces, como en el mercado, de "apuestas probabilísticas".

En las sociedades reales, pretender realizar ese tipo ideal implica separar el campo político, donde se encuentran los ciudadanos, de los campos económico, social y cultural de la sociedad como un todo, donde los individuos y grupos concretos desenvuelven sus vidas, campos en que no se requeriría la igualdad de acceso a la riqueza, la no discriminación, etc. Es más, cuando se postula la coherencia entre democracia formal y economía formal, la mercantilización generalizada refuerza la tendencia a que la sociedad se polarice entre ricos y pobres, entre incluidos y excluidos, lo que constituye una pobre base para la igualación del poder ciudadano.

En cuanto a la democracia realmente existente, el adjetivo "real" se ha utilizado principalmente para marcar sus distancias respecto al tipo ideal de la democracia liberal. Lo que implica que es desde este paradigma que se tiende a analizar y juzgar las formas políticas reales. Correspondería ubicar "fallas" ocasionales en su implementación concreta, equivalentes a las fallas del mercado de la economía formal que, una vez identificadas, podrían ser encapsuladas y reintegradas por el principio de mercado. ${ }^{12}$

La formación de monopolios es una tendencia intrínseca del mercado libre, que la teoría económica formal considera una anomalía, mientras que la Economía Crítica identifica como una tendencia intrínseca comprobada de este sistema. Otro tanto ocurre con la corrupción de la democracia formal, entendida no meramente como apropiación privada de recursos públicos sino como la sustitución de la voluntad de los representados por la de los representantes particulares, privatizando la política (DUSSEL, 2006). Las leyes antimonopolios o las que impiden la reelección de los gobernantes no anulan esas tendencias, meramente las contrarrestan parcialmente.

En lo que hace a propuestas alternativas a la democracia real, puede reafirmarse el modelo de democracia formal, del mismo modo que lo hace el neoliberalismo con el mercado: si la democracia o el mercado reales producen efectos socialmente destructores, lo que hace falta es más democracia formal y más mercado autorregulado siguiendo las respectivas utopías. Otra opción es proponer una alternativa institucional que rescata parte de

\footnotetext{
${ }^{12}$ No es otra cosa lo que se intenta, por ejemplo, mercantilizando los derechos a contaminar. Su equivalente político incluye las diversas reformas de los sistemas de representación para corregir las condiciones que vuelven ficticia la supuesta igualdad entre los ciudadanos (ejemplo: las cuotas de representantes por género).
} 
esa democracia ${ }^{13}$ pero propone convalidarla no solo por el cumplimiento de sus normas utópicas sino por el contenido empírico verificado históricamente, por sus efectos sobre los grupos particulares y sobre la sociedad en su conjunto.

Retomamos aquí el término de democracia sustantiva, ${ }^{14}$ que se diferencia del de democracia formal, porque no se limita a un procedimiento (la forma) ni acepta que a partir de la competencia entre los intereses particulares se construye un interés general que siempre lleva a la mejor de las situaciones para la sociedad. Podría decirse que la democracia formal no tiene en cuenta los fines y logros predeterminados del gobierno, mientras que la sustantiva hace caso omiso de los procedimientos si se cumplen los fines. Pero eso no es así.

Por un lado, ambas se orientan según determinadas finalidades que serían inviolables (la prosecución de la libertad individual negativa y finalmente la protección de la propiedad privada en un caso, el logro de una vida digna en sociedad y la valoración de los comunes en el otro). De hecho, en lo fundamental, cada sistema de gobierno conlleva un conjunto y una jerarquización distinta de los derechos humanos. Es decir que la democracia formal puede ser la más adecuada para un dado sistema de derechos humanos pero no para otro, con lo que la diferencia en última instancia es entre uno u otro sistema de derechos. (HINKELAMMERT, $1987)^{15}$

Por otro lado, la sustancia tiene necesariamente forma, pero lo decisivo es lo sustantivo, y desde allí se valora la eficacia de las formas. Se proponen procedimientos, por supuesto, que en buena medida resultan del análisis crítico de la democracia realmente existente bajo el paradigma liberal. Por ejemplo, la democracia sustantiva puede admitir la posibilidad de que el pueblo delibere y se manifieste generando legitimidad más allá de los mecanismos de la democracia representativa. ${ }^{16}$ En todo caso, ninguna forma de decisión y acción colectiva garantiza determinados resultados. El concepto de democracia sustantiva no supone otras reglas fijas sino que admite una variedad de formas de acción y decisión colectiva, incluidas las propias de la democracia formal. Sí requiere que la efectivización de sus formas sea conducente a la reproducción y desarrollo de la vida, es decir, al sostenimiento de una economía sustantiva que, a su vez, no puede darse sin tal democracia.

Así, una democracia sustantiva supone, a la vez que seguir las reglas de la democracia representativa como contribución a la producción de legitimidad, una extendida participación directa - como individuos o bajo diversas formas de agregación de actores colectivos- en las

\footnotetext{
13 “La tarea de la izquierda no puede por tanto consistir en renegar de la ideología liberal-democrática sino al contrario, en profundizarla y expandirla en la dirección de una democracia radicalizada y plural." (LACLAU y MOUFFe, 1987).

${ }^{14}$ Proponemos tomar este concepto como correspondiente al de economía sustantiva, entendiendo que no puede haber un principio ético de última instancia distinto para cada campo de la acción humana. En consonancia con esto, ver el artículo de Yamandú Acosta "Democracia sustantiva” (ACOSTA, 2008).

${ }^{15} \mathrm{La}$ democracia liberal ha tendido a dar la mayor jerarquía a los derechos civiles y políticos del individuo, pero las luchas sociales han ampliado el sistema de derechos incluyendo los sociales, económicos y culturales. Hoy puede decirse que se hace perentorio avanzar en derechos que tienen que ver no solo con la vida digna de los individuos y comunidades sino con el cuidado de la diversidad de formas de vida, de los seres humanos y del resto de la naturaleza. El proyecto neoconservador que es hoy dominante pretende regresar a la absolutización de los derechos individuales, con una libertad irrestricta que permite reproducir y expandir la desigualdad en base a la propiedad privada.

16 Justamente, esta forma de expresión de la voluntad popular ha sido ejercida y en general aceptada en los procesos estudiados, habiendo sido desencadenante en cuatro de los casos de la asunción y confirmación de gobiernos con orientación popular. Sin embargo, esta relación entre los nuevos gobiernos y las movilizaciones o movimientos sociales no ha sido virtuosa en todas las circunstancias y cuestiones en juego.
} 
decisiones de gobierno, en la gestión de lo público, en la administración de justicia, en definir los objetivos de la sociedad, en el control de las tendencias de los representantes a sustituir la voluntad del pueblo soberano, entre otras cosas instituyendo la revocabilidad y rotación de los mandatos, la afirmación de las responsabilidades de los ciudadanos y no solo de sus derechos y por último, la visibilidad de lo público. Retoma de la cultura de los pueblos originarios que no se trata de competir por el poder ejerciendo el derecho a ser elegido sino de asumir la responsabilidad de representar a la comunidad en caso de ser elegido por ésta.

Todo ello tanto para minimizar el riesgo de apropiación del poder por los representantes, como para satisfacer de manera directa una necesidad compleja: la que conjuga participación, reconocimiento del propio saber, aprendizaje y pertenencia a una comunidad. Otra razón por la que las formas no le son indiferentes: una dictadura, aunque garantice el acceso a los bienes requeridos para satisfacer las necesidades "básicas", impide realizar otras necesidades que requiere una vida digna, como la de autodeterminación.

Aún en ese caso, su criterio distintivo no es el del mero cumplimiento de una determinada combinación de formas jerarquizadas, sino el de la obtención de los resultados deseados o al menos de la generación de condiciones para hacerlos probables. La deseabilidad de esos resultados es determinada éticamente: la reproducción de la vida digna en comunidad (siendo la dignidad definida en cada situación histórica) como un deber ser innegociable, como una condición necesaria para que una comunidad humana pueda sostenerse sobre sus propias bases, sociales y naturales. El análisis de lo posible en cada momento, reconociendo que hay límites a aquel imperativo, va a permitir evaluar las distintas opciones reales de acción o de institucionalización, según su acercamiento a la mejor sociedad posible.

$\mathrm{Al}$ respecto, Dussel propone definir la vida como "[...] el modo de realidad del sujeto ético, [que]da contenido a todas sus acciones, determina el orden racional y también el nivel de las necesidades, pulsiones y deseos, [y] constituye el marco dentro del cual se fijan fines." DUSSEL). Por su parte, Hinkelammert agrega que ese principio ético no es un valor moral relativo sino que está sustentado como un juicio de hecho irrefutable: sin reproducción de la vida no hay fines, no hay gobierno, no hay ninguna democracia.

Desde esta perspectiva, el interés de todos consistiría en que convivamos reproduciendo nuestra vida material y espiritual, acercándonos a las mejores condiciones de posibilidad de la vida humana. Esto incluye, de manera cada vez más evidente, una relación restitutiva y no extractivista con la naturaleza exterior. Sin embargo, salvo que se cumplan condiciones como la plena información sobre los diagnósticos, las opciones y las consecuencias que acarrean (aunque sea probabilísticamente), el sistema político formal no garantiza que en la práctica la sociedad, alienadamente, no decida suicidarse. Por ejemplo, permitiendo o impulsando la adopción de tecnologías y modos de consumo con una mirada cortoplacista con criterios de la economía formal, que polaricen la sociedad o reduzcan la posibilidad de vida de las próximas generaciones.

En resumen, una democracia sustantiva sería entonces la que hace más probable que se cumplan las condiciones para que se logre la finalidad de la economía sustantiva. No puede ser un mero procedimiento para definir algún "interés general" sino que debe tener como condición y como objetivo la vida de todas y todos, en libertad positiva (asociados solidariamente en comunidad nos emancipamos). 
Para el modelo de democracia formal el pueblo es el subconjunto de la población que cumple las condiciones que se establecen para ser considerado ciudadano, cualquiera sean sus diferencias en otras dimensiones. Para Dussel, en cambio, el pueblo es el "[...] bloque social de los oprimidos y excluidos [...]" (DUSSEL,), en contraposición a las elites dirigentes. Para la democracia sustantiva, tal como la entendemos aquí, y siguiendo a Laclau, el pueblo es una construcción histórica, estructurada y constituida de manera contingente, que incluye pero no se agota en aquel bloque social. Para una lectura política, la configuración de la hegemonía del campo popular no está determinada por el desarrollo de una clase o estrato esencial, es coyuntural y variable, tanto en la referencia a clases como a otras formas de agregación social (etnias, regiones, géneros, capas etáreas, etc.), y de forma similar respecto a las formas de organización (sindicatos, movimientos sociales, sus formas de presentación y representación). Tal hegemonía puede ser tanto interna al campo popular como a la sociedad en su conjunto.

Para la democracia formal el Estado es un sub-sistema institucional cuya estructura y relación con la sociedad política y la sociedad en general está dada. En la percepción de algunas izquierdas de la modernidad se trataría de tomar, de ocupar esas estructuras donde estaría localizado el poder, para implementar otro proyecto social y particularmente económico. Para la democracia sustantiva el Estado es una construcción continua que, particularmente en épocas de transición sistémica, requiere ser reinventado (SOUSA SANTOS, 2005). A nuestro juicio, esto supone incluir diversas formas de organización y participación popular, otra jerarquización del sistema de derechos humanos a garantizar y otros modos de gobernar ("mandar mandando" o "mandar obedeciendo" como plantean los Zapatistas) y hacerlo dentro de una lógica populista (LACLAU, 2005). Una reinvención que implica, entre otras cosas, establecer una relación de diálogo y responsabilidad conjunta entre el aparato de Estado y la sociedad civil, contrarrestar la tendencia del Estado a clasificar fragmentando, institucionalizar las respuestas a las demandas parciales. Una relación que se hace posible a partir de las experiencias reflexivas que construyen comunidades y autonomías en el interior del mismo pueblo movilizado y organizado de manera articulada como sujeto político, colectivo y diverso.

\section{CONCEPTOS GENERALES: REVOLUCIÓN}

En cuanto al concepto de revolución, simplemente vamos a seguir la diferenciación usual respecto al de evolución. Este último postula como ley histórica para la sociedad un desarrollo lento, cuasi-natural, que responde a procesos legaliformes como los que se presuponían para la naturaleza en la primera mitad del siglo XX. Formalmente podría verse una coincidencia entre dos polos del pensamiento político occidental: el finalismo. Al final de la evolución estarían el comunismo o el mercado total. Desde una mirada de largo periodo, las luchas sociales (y las consideradas "revoluciones") serían parte del mismo proceso de evolución, a lo sumo acelerándolo.

Otra concepción concibe que no hay un final ineluctable, que hay puntos de ruptura del sistema imperante, pero que no está predeterminado hacia donde se orientará efectivamente el nuevo sistema, mucho menos que las transformaciones sean irreversibles. En esto se supone que la sociedad como forma de la vida persiste. En los plazos de la política, y a partir de nuestro capitalismo, la utopística se concreta, entre otras cosas, en una transformación voluntaria de los sistemas institucionales que venían haciendo posible (aún con 
contradicciones) la reproducción de las sociedades existentes. ${ }^{17}$ Tal transformación puede ir desde la pretensión utópica de acabar con toda institución (anarquismo) hasta sustituirlas por otras superiores desde la perspectiva de determinados principios éticos o de proyectos interesados. En ningún caso se trataría de una sustitución ingenieril de un sistema institucional por otro predeterminado. Transformar un sistema institucional es un proceso de transición, desigual, combinado y no igual en distintas sociedad y momentos históricos. El papel de la política democrática será interpretar colectivamente, en cada situación concreta, qué vías de acción representan mejor ese imperativo ético y evaluar o contribuir a crear las condiciones de factibilidad para que puedan realizarse.

Avanzar hacia una democracia y una economía sustantivas requeriría ir desplazando o subordinando la institucionalidad instalada por el proyecto neoconservador con su ideología económica neoliberal, que pretendió reducir la política a una combinación entre el dominio de las minorías sobre las mayorías y "la administración de las cosas". La reinstalación de la política, como voluntad transformadora orientada por el principio de reproducción y desarrollo de la vida (aunque ni la retórica política ni los programas de acción inmediata lo pongan en esos términos), implica que los gobiernos superen su preocupación por mantener equilibrios y minimizar conflictos y asuman que se trata justamente de desequilibrar el campo de fuerzas políticas a favor del pueblo. Este sería un criterio para establecer equivalencias o diferencias entre los procesos nacionales que hoy se dan en América Latina: se avanza de manera desigual en la democratización y en una nueva racionalidad económica, o en ambas? Quienes son los sujetos que realizan esos procesos? ${ }^{18}$

Las sociedades capitalistas periféricas, o como se quiera llamarlas (esto no es menor pero ahora no entramos a ese asunto), cargadas de negatividad desde la perspectiva de esta ética, se vienen reproduciendo porque están sostenidas mediante arreglos institucionales, ya sea por imposiciones, por convenciones o tradiciones, por hegemonías o por miedos. Revolucionarlas implicaría transformar de manera irreversible esos sistemas institucionales y esa cultura política instalando otro principio ético como orientación de última instancia.

En esto hay que tomar en cuenta que las sociedades latinoamericanas no han experimentado una mercantilización comparable a la de los países capitalistas industrializados. En todo caso, son capitalistas en tanto, como descubrió Marx, la lógica intrínseca del capital y los valores y comportamientos de quienes lo encarnan sobredeterminan los de otras formas de sociabilidad y acción económica. Sin embargo, más empíricamente y para el conjunto de América Latina, puede haber funcionalizado pero en ningún caso ha eliminado de raíz estas formas logrando un grado de homogeneización equivalente al de aquellos países.

El período del desarrollismo en América Latina muestra que desde la política se transformó la economía, en buena medida con el Estado cumpliendo el papel de modernizador, racionalizador $\mathrm{y}$, entre otras cosas, creador de las condiciones para una economía con mercado, extendiendo su alcance a lo largo de las actividades y territorios. En

\footnotetext{
${ }^{17}$ Para Wallerstein, la utopística consiste en "la evaluación seria de las alternativas históricas, el ejercicio de nuestro juicio en cuanto a la racionalidad material de los posibles sistemas históricos alternativos. Es la evaluación sobria, racional y realista de los sistemas sociales humanos y sus limitaciones, así como de los ámbitos abiertos a la creatividad humana. No es el rostro de un futuro perfecto (e inevitable), sino el de un futuro alternativo, realmente mejor y plausible (pero incierto) desde el punto de vista histórico. Es por lo tanto, un ejercicio simultáneo en los ámbitos de la ciencia, la política y la moralidad” (WALLERTEIN, 1998, p. 3-4).

${ }^{18}$ Aquí podríamos remitirnos al debate entre Haya de la Torre y Mariátegui sobre el papel del Estado (FRANCO, 1983; ARICÓ, 1978).
} 
todo caso un mercado incompleto, en primera instancia interno o nacional, regulado e inducido por el Estado, ya fuera por razones instrumentales (como la creación temporaria de condiciones para que realmente pueda funcionar) o por la búsqueda de soberanía nacional. ${ }^{19}$

Bajo el reciente mandato neoliberal, esa sociedad heredada venía simulando separar las esferas política y económica, en particular reduciendo la interferencia del Estado sobre la libertad irrestricta de individuos emprendedores. Lo que en realidad se proponía era que, en nombre de la modernización, la política construyera las condiciones para la integración de nuestras economías a la economía global de mercado, si fuera necesario mediante la violencia de las dictaduras o del ajuste infinito justificado por una deuda impagable.

Para la economía sustantiva, como artefacto bajo control social el mercado no es un problema. En sociedades complejas es un mecanismo ineludible de coordinación que requiere regulaciones que serán siempre imperfectas. Sin embargo, cuando se pretende absolutizarlo se vuelve destructor de la vida.

Para la doctrina neoliberal, un mejor funcionamiento del mercado requiere la generalización de comportamientos egoístas y utilitarios, y cuando tales valores no son parte de la cultura deben imponerse civilizando las sociedades. Llevamos décadas de tal "acción civilizatoria" y están comprobados sus efectos destructores de una cohesión social que, no pudiendo nunca ser completa, sea suficiente. En nombre de la ética de la vida se requiere actuar orientados por otro proyecto de sociedad alternativa, que tenga credibilidad y pueda realizarse lo mejor posible.

La cuestión social ha sido planteada como la de la fragmentación de la sociedad moderna por los efectos destructores del mercado capitalista liberado, autonomizado de controles sociales. Sin embargo, reencastrar la economía en la sociedad no puede interpretarse como recuperar la cohesión de la sociedad concreta preexistente, construida y a la vez puesta en crisis por el proyecto político neoconservador, sino que supone la transformación de esa misma sociedad que venía predominantemente orientada por la ética del mercado. Aunque se prevé que, de seguir profundizándose, el acercamiento global al "mercado total" destruiría toda forma de sociedad humana, el problema que enfrentamos no es abolirlo para salvar una sociedad ahistórica, abstracta, sino actuar para controlarlo y así posibilitar la existencia de una sociedad concreta, vivible y sostenible. La disyuntiva entre una acción centrada en el Estado o en la sociedad es una falsa opción. Lo que se requiere es una transformación democratizante del Estado en sentido ampliado que asegure una mejor integración social de la economía.

Antes que oponer reforma y revolución, consideramos que una transformación perdurable de la sociedad no es posible sin una sucesión coherente y paulatinamente consolidada de reformas del sistema institucional que pueden tomar fuerza con su creciente consistencia y centralidad. Para dar un ejemplo, la justicia y la solidaridad social, incompatibles con una economía orientada por la utopía del mercado perfecto, pueden comenzar a ser (re) introducidas en sectores de la economía por la combinación de acciones micro-meso-sistémico, en que se den varias condiciones:

\footnotetext{
${ }^{19}$ Lejos de ser un avance irreversible en el sendero evolutivo del desarrollo al estilo eurocéntrico, las últimas décadas han mostrado que en buena medida puede ser retrotraído a los modelos primario importadores previos. Sin embargo, esto no ha borrado totalmente una cultura y un imaginario del desarrollo económico nacional portados por sectores de la sociedad que participaron de aquel proceso. Imaginario que evidentemente se actualiza por los mismos gobiernos de las "nuevas izquierdas".
} 
- A los participantes les conviene (interés material) incorporar tales relaciones en ese sector. El problema no es que haya comportamientos utilitarios sino que se aplique indiscriminadamente esa motivación sin asumir responsabilidad por las consecuencias de los actos individuales (utilitarismo).

- Dichos sectores incorporan motivaciones complementarias (no necesariamente antagónicas) a la del interés material, y existen participantes con otros valores (comuneros, ideológicos, religiosos) que son parte de una comunidad moral que los sustenta en sus convicciones.

- Como ciudadanos organizados, los agentes económicos pueden intervenir correctivamente en los resultados de los mercados en que participan (monopolios, riqueza/pobreza, externalidades destructivas), lo cual requiere al menos un sistema político formalmente democrático.

- El Estado democrático asume el mandato de garantizar los derechos sociales de todas y todos, impulsando o acompañando el desarrollo de formas complejas de economía solidaria.

- Se produce un cambio en la correlación de fuerzas en el campo económico que permite resolver favorablemente los conflictos que genere el avance de las prácticas de economía social y solidaria. La naturaleza y profundidad de esos conflictos marcará el alcance de las transformaciones que se vayan dando, las que necesariamente abarcan distintas dimensiones del sistema imperante.

Sin afirmar que lograr tales condiciones constituyan de por sí una revolución, sin duda se avanzaría en una transición que cuestione el proyecto neoconservador y muestre que estas realidades contienen (heterotopía) experiencias significativas y aprendizajes que muestran el potencial para una economía socialmente integrada por lazos de solidaridad y la encarnación de una ética de responsabilidad por la vida. Resaltamos que una transición efectiva supone que los avances hacia una ESS no pueden ser meramente por un mejoramiento en la situación material de los actores populares involucrados (nivel micro o incluso meso) sino que supone un avance estructural con pretensión universal de la situación de los sectores populares, lo que no puede hacerse sin la mediación política del Estado.

\section{LAS RELACIONES ENTRE ECONOMÍA, DEMOCRACIA Y REVOLUCIÓN}

Desde los 70', bajo el comando del proyecto político neoconservador, en muchos casos bajo dictaduras, nuestras economías sustentaron abiertamente los privilegios de minorías y el empobrecimiento de las mayorías. Ante la resistencia popular o al menos el voto, muchos de estos procesos pasaron a ser acompañados por una democracia "de baja intensidad", aún sometida a los condicionamientos de los organismos financieros internacionales, lo que parecía justificar la continuidad de ese programa y su propuesta económica neoliberal.

Esa democracia y esa estructura económica "reales" se correspondían. ${ }^{20}$ Postulamos que, necesariamente, transformar una supone transformar la otra. Sin embargo, si las revoluciones son procesos de larga duración protagonizados por sujetos de base popular, lo político prima. Las democracias reales de las que emergieron las nuevas izquierdas eran deformes e incompletas, a tal punto que su reciente perfeccionamiento según los principios de

${ }^{20}$ Ver situación “ 0 ” en el anexo. 
la democracia formal cabal podría ya entenderse como una fase del proceso para institucionalizar una democracia sustantiva. Sin embargo, tal proceso podría quedar cristalizado en las instituciones de la democracia formal y una economía formal acompañadas apenas por programas de inserción marginal de las víctimas. La cuestión es si tal situación podría perdurar sin llevar a regresiones o a fuertes transformaciones adicionales.

De lo que se trata aquí es de determinar si se están dando procesos mediata o inmediatamente orientados a la construcción de una democracia sustantiva, condición para definir, sostener y profundizar las transformaciones económicas por las que se suele caracterizar estos procesos. ${ }^{21}$ Es decir, aun si buena parte de la tarea de estas nuevas izquierdas gobernantes es transformar lo económico, las transformaciones políticas priman. Una sociedad profundamente democrática integra su economía de modo que todas y todos puedan tener una vida digna. Pretender lograr esto sin avances hacia una democracia sustantiva puede dar un resultado de mayor justicia pero de gran vulnerabilidad para sostenerse como nuevo orden. ${ }^{22}$

Por otro lado, no puede desarrollarse una democracia sustantiva, ni tampoco sostenerse la formal según su tipo ideal, en un contexto de necesidades no realizadas. Hasta cierto límite, la democracia real, de "baja intensidad" pudo funcionar sobre bases de pobreza y desigualdad, pero cuando se rebasaron los límites de lo aguantable, la fachada de democracia formal no fue suficiente y los sectores oprimidos se rebelaron. Tampoco una democracia formal cabal podría consolidarse sobre esas bases.

A la vez, a inicios del Siglo XXI, despejada la opción de asaltar el Estado, tampoco es posible tomar las decisiones colectivas que requiere una transformación económica progresiva si no hay al menos un inicio de democracia formal. Esto supone, por ejemplo, un gobierno elegido por el voto popular y una voluntad política para producir inmediatamente una mayor justicia distributiva y el mejoramiento de todos los indicadores sociales a los sectores populares golpeados por el neoliberalismo. La legitimidad inicial, provista por la acción popular que posibilitó esos gobiernos, debe ser sostenida por cambios inmediatos en las condiciones de la vida cotidiana de esos sectores.

Sin embargo, consideramos necesario avanzar en la institucionalización de formas de participación autónoma e informada de las mayorías en decisiones que marcan el rumbo de estos procesos, como la de definir y concretar en las políticas públicas qué es el bien común (Buen vivir?) y cómo avanzar en su consecución. ${ }^{23}$ Esto implica que en su desarrollo y consolidación primará estratégicamente que sea el pueblo organizado el que dirija el proceso complejo y prolongado que incluye la transformación económica, tanto directamente como con la mediación (sin sustitucionismo) del Estado. ${ }^{24}$

\footnotetext{
${ }^{21}$ Esto no implica suponer que hay una secuencia necesaria: democracia real $\Rightarrow$ democracia formal $\Rightarrow$ democracia sustantiva. Otra cosa es que la construcción de una democracia sustantiva pueda incluir, en su procesamiento y/o en su estructura como tal, el recurso a mecanismos propios de la democracia formal ideal.

${ }^{22}$ Como excepción, para una definición de necesidades básicas, el socialismo cubano resolvió las necesidades igualitariamente sin un sistema de democracia formal a cabalidad.

${ }^{23}$ A nuestro entender, el Buen Vivir, lejos de limitarse al acceso de todas y todos a bienes materiales, requiere formas de autogobierno que superan las de la democracia formal.

${ }^{24}$ Sin pensar en fases prefijadas, habría que diferenciar entre los tiempos de constitución de un bloque nacionalpopular en control del Estado heredado y los de efectiva trasformación del Estado, del sistema democrático y de las estructuras económicas. Por otro lado, la globalización del capital y el poder implican que los límites de la dimensión nacional de estos proyectos imponen la conformación de sujetos y modos de acción popular que
} 
Una posibilidad lógica es que el gobierno regule y redirija la economía heredada en el marco de una democracia formal (institucionalización de una mayor apropiación estatal del excedente de las actividades extractivas y del mecanismo de redistribución social y sectorial progresiva; reconocimiento y apoyo a formas económicas no capitalistas) ganando un tiempo político y un desarrollo organizativo (afirmación de la legitimidad de las nuevas izquierdas gobernantes y consolidación de los nuevos sujetos sociopolíticos) necesarios para emprender profundas transformaciones económicas y la radicalización de la democracia. ${ }^{25}$

Aunque puede haber cambios parciales muy significativos (como es el caso de la nacionalización de la renta internacional y la distribución más igualitaria del ingreso por la vía fiscal, del control de los salarios, de la intervención en los precios relativos y de otros por el estilo) no son transformaciones estructurales que afecten el funcionamiento y los resultados del sistema económico (y por tanto societal) como un todo, lo que cabría llamar "Revolución". Esto supondría actuar no solo sobre la distribución y circulación, sino también sobre las relaciones sociales de producción, sobre las relaciones de propiedad, sobre las formas de organizar el trabajo, sobre la definición social de riqueza, sobre la mercantilización de la tierra y el trabajo, sobre los modos de consumo. Y, dado que lo económico no puede desenraizarse totalmente de la sociedad, supone transformaciones radicales de la política, de la cultura. ${ }^{26}$ En cualquier caso, establecer el sentido y alcance de cada proceso requiere un "análisis concreto de cada situación concreta".

Si bien estos ejercicios lógicos son útiles, es preciso no caer en la pretensión de optar a priori entre etapas predeterminadas como si fueran metas a cumplir y pudieran elegirse los caminos óptimos; como si se tratara de procesos causales secuenciales. Los procesos reales que se están desenvolviendo en estas sociedades generan contradicciones y, en un mediano plazo (tres o cuatro períodos de gobierno del bloque nacional-popular?), en el contexto global son vulnerables, y queda abierto un espectro de diversos desarrollos posibles, incluso regresivos. Basta recordar el caso de los gobiernos presididos por Lugo Paraguay y de Zelaya en Honduras. Como se dijo antes, la consolidación de una democracia sustantiva parece ser una condición necesaria para el sostenimiento, extensión y profundización de estos procesos.

\section{BIBLIOGRAFÍA}

ACOSTA, Yamandú. Democracia sustantiva. In: Hugo BIAGINI y Arturo Andrés ROIG, (Directores). DICCIONARIO DEL PENSAMIENTO ALTERNATIVO. Buenos Aires: Biblos-UNLA, 2008.

\footnotetext{
superan el ámbito de los estados-nación. Esto daría a los procesos nacional-populares el carácter de transiciones a otros modos de construcción de lo social a nivel global.

25 “... para nuestros procesos, la radicalidad democrática es el método para generar más y mejor democracia liberadora de las fuerzas creadoras e insurgentes de nuestros pueblos, imprescindibles para la revolución. Una revolución simplemente política puede consumarse en pocas semanas. Una revolución social y económica exige años, los indispensables para penetrar en la conciencia de las masas para organizar las nuevas estructuras, hacerlas operantes y ajustarlas a las otras. No es posible destruir una estructura social y económica, una institución social preexistente, sin antes haber desarrollado mínimamente la de reemplazo. Si no se reconoce esta exigencia del cambio histórico, la dialéctica de la realidad se encargará de alterarla y subvertir el orden." (TORRES GALARZA, 2014)

${ }^{26} \mathrm{Si}$ en algún lugar hablamos de "revolución económica", revolución política" o revolución cultural" es para indicar la multidimensionalidad del sistema en transformación y la posibilidad de avances desiguales en ese proceso.
} 
ARANCIBIA, Inés. Necesidades del capital o necesidades de la vida. Argumentaciones desde la Economía del Trabajo. Tesis de Maestría, MAES/UNGS, 2013.

ARICÓ, José. Prólogo a Mariátegui y los orígenes del marxismo latinoamericano. México: Cuadernos de Pasado y Presente, 1978.

CAILlÉ, Alain. Teoría antiutilitarista de la acción. Buenos Aires: Waldhuter Editorial, 2010.

CORAGGIO, José; LAVILLE, Jean-Louis (Org). Reinventar la Democracia en el Siglo XXI. Para un diálogo Norte Sur. Buenos Aires; Quito: UNGS/IAEN/CLACSO/DR\&RD, 2014 "a".

CORAGGIO, José. Otra política, otra economía, otras izquierdas. In: CORAGGIO, José; LAVILLE, Jean-Louis (Org). Reinventar la Democracia en el Siglo XXI. Para un diálogo Norte Sur. Buenos Aires; Quito: UNGS/IAEN/CLACSO/DR\&RD, 2014 “b”.

CORAGGIO, José. Principios, instituciones y prácticas de la economía social y solidaria. In: CORAGGIO, José. Economía Social y Solidaria. El Trabajo antes que el Capital. Quito: Abya Yala, 2011.

DUSSEL, Enrique. 20 tesis de política. México: CREFAL/Siglo XXI, 2006.

DUSSEL, Enrique. Dieciséis tesis de economía política. Interpretación filosófica. México: Siglo XXI, 2014.

FRANCO, Carlos. Haya y Mariátegui: Los discursos fundadores. In Carlos FRANCO (Coord.), El Perú de Velasco. (Tomo I). Lima, 1983.

HINKELAMMERT, Franz; MORA, Henry. Economía, sociedad y vida humana. Los Polvorines: UNGS/Altamira, 2009.

HINKELAMMERT, Franz. Democracia, estructura económico social y formación de un sentido común legitimador. In: HINKELAMMERT, Democracia y totalitarismo, Costa Rica: DEI, 1987

LACLAU, Ernesto; MOUFFE, Chantal. Hegemonía y estrategia socialista. Hacia una radicalización de la democracia. Madrid: Siglo XXI Editores, 1987.

LACLAU, Ernesto. La razón populista. México: Fondo de Cultura Económica, 2005.

POLANYI, Karl. La economía como proceso instituido. In: POLANYI, Karl. Textos escogidos. Los Polvorines: UNGS/CLACSO, 2012.

MAX-NEEF, Manfred; ELIZALDE; HOPENHAYN. Desarrollo a Escala Humana: Una opción para el futuro. Revista Development Dialogue, CEPAUR/ Fundación Dag Hammarskjöld, Uppsala, número especial. 1986.

TORRES GALARZA, Ramón. Democracias en Revolución, Revoluciones en Democracia. In: CORAGGIO, José.; LAVILLE, Jean Louis (Orgs). Reinventar la Democracia en el Siglo 
XXI. Para un diálogo Norte Sur. Buenos Aires;y Quito: UNGS/IAEN/CLACSO/DR\&RD, 2014

WALLERSTEIN, Immanuel. Utopística o las opciones históricas del siglo XXI. México: Siglo XXI editores, 1998.

WEBER, Max. Economía y Sociedad. México: Fondo de Cultura Económica, 1964. 